\title{
Early maternal influences on stress circuitry: implications for resilience and susceptibility to physical and mental disorders
}

\author{
Nikolaos P. Daskalakis ${ }^{1,2,3}$ * and Rachel Yehuda ${ }^{1,2,4}$ \\ ${ }^{1}$ Traumatic Stress Studies Division, Department of Psychiatry, Icahn School of Medicine at Mount Sinai, New York, NY, USA \\ ${ }^{2}$ Mental Health Patient Care Center, James J. Peters Veterans Affairs Medical Center, Bronx, NY, USA \\ ${ }^{3}$ Laboratory of Molecular Neuropsychiatry, Department of Psychiatry, Icahn School of Medicine at Mount Sinai, New York, NY, USA \\ ${ }^{4}$ Department of Neuroscience, Icahn School of Medicine at Mount Sinai, New York, NY, USA \\ *Correspondence: nikolaos.daskalakis@mssm.edu \\ Edited and reviewed by: \\ Hubert Vaudry, University of Rouen, France
}

Keywords: early life stress, HPA axis, vulnerability, resilience, maternal

Experiences in early life result in enduring and sometimes permanent differences in how the central nervous and endocrine systems function. These changes are referred to as developmental programing, and have numerous consequences for susceptibility to physical and mental disorders, which involve central nervous and endocrine systems. These effects may depend on genetic factors, but more importantly, involve epigenetic mechanisms, which can change the function of the gene independently of genotype. Environmentally induced epigenetic changes alter gene expression and function, and their outcome leads to adaptive or maladaptive expressions, depending on the specific environmental context of the individual (1).

In this Frontiers Research Topic "Programing the hypothalamic pituitary adrenal (HPA) axis by early life experience: mechanisms of stress susceptibility and adaptation," we have assembled a comprehensive selection of original research, mini reviews, and review articles that describe prenatal and postnatal maternal influences on stress response systems in offspring. This is an emerging and critical area in neuroendocrine science as it is becoming increasingly clear that much of the variance associated with biological alterations in physical and mental disorder may be accounted for by maternal history and experiences in the womb or in early postnatal life. While such influences have been broadly acknowledged, until recently, it has been difficult to measure the effects of these maternal influences on offspring. Epigenetic marks can be measured and provide a quantification of relevant early environmental influences. Carefully designed studies can then parse out the origin of early influences.

In the opening paper of the volume, Daskalakis and Yehuda systematically review the methodologies employed to study epigenetic effects of early adversity (2). They focus on studies of the most studied genomic region in human stress-related diseases, the exon $1_{F}$ promoter of the glucocorticoid receptor (GR) gene. The discussion is meant to present a series of issues that influence quantitative methylation analyses (method, tissue type, region of interest). It is important in an emerging field to discuss such issues since they can result in variable results from laboratory to laboratory. The authors make the important point that there may be site-specific accommodations of different adversity factors in different $\mathrm{CpG}$ sites within a promoter-based $\mathrm{CpG}$ island, leading to a greater complexity of data analysis and interpretation than is currently the standard. Finally, this review paper also includes unpublished data that extend the transgenerational effects previously observed in this region (3) by demonstrating site-specific effects based on maternal and/or paternal PTSD.

After this focused review, two review papers provide an overview first of the effects of early adversity on major depression, as an example of a critical psychiatric outcome, and second on the effects of early adversity on metabolic outcomes. Hornung and Heim (4) summarize recent human studies implicating gene by early life stress interactions in vulnerability and resilience for depression. The authors chose the term "intermediate phenotype" throughout the paper in order to emphasize the mediational character of some phenotypic features, which result from gene by environment interactions and may lead to depressive symptoms. Maniam et al. (5) using animal and human data support that early adversity induced maladaptation of the HPA axis will have negative impact on energy metabolism in the presence of chronic stress or unfavorable metabolic conditions in later-life leading to vulnerability to metabolic diseases. To this end, authors have attempted to review the relevant literature, with attention paid to findings dealing with metabolic/body weight measures. They further propose a mechanism whereby the cross-talk between HPA axis and altered glucocorticoid (GC) metabolism in the liver (by 11-beta hydroxysteroid dehydrogenase Type 1) may likely mediate the metabolic outcomes of early life stress.

Following these overviews, papers were divided according to the developmental time window in which adversity was present. Two original research articles describe the effects of prenatal maternal exposures to alcohol and GCs on stress-related neurocircuits. Raineki et al. (6) reveal complex sexual dimorphisms by providing a comprehensive (constrained principal component) analysis of the neural activity (by $c$-fos expression) in amygdala, hippocampus, medial prefrontal cortex, and paraventricular nucleus of hypothalamus in response to acute stress in male and female offspring of dams exposed to alcohol or two control conditions in gestation (gestation day 1-21), which where additionally exposed to a 10-day chronic mild stress paradigm in the peripubertal 
period. Borges et al. (7) find that prenatal maternal exposure to dexamethasone (gestation days 18 and 19) increased the activity of two regions that belong to the mesopontine cholinergic system (laterodorsal and pedunculopontine tegmental nuclei) associated with enhanced behavioral stress vulnerability (anxiety behavior including fear-associated ultrasonic calls). The review by de Kloet et al. (8) complements the Borges paper by focusing on the impact of perinatal GC exposure on the developing HPA axis and the balance between GR and mineralocorticoid receptor. The authors review animal and also clinical research on perinatal disturbances by GC administration and possible intervention strategies.

Postnatal stress in rodents also exerts lasting effects on the stress system as well as on other brain systems. Daskalakis et al. (9) provide original data on strain-dependent differences in the immediate effects of maternal deprivation on the neonatal HPA axis response. While maternal deprivation causes a disruption of the neonatal stress hyporesponsive period in both mice strains studied, one strain was more affected calling for future studies on later-life consequences of early postnatal stress based on genetic background. Loi et al. (10) describe how hippocampal neurogenesis is affected by early life stress in rodents in an ageand sex-dependent manner, and provide novel data showing that normalization may be possible through GC-based interventions during critical stages of brain development. Brief treatment with mifepristone, a GR antagonist, on postnatal days 26-28 protected female rats against the effects of maternal deprivation (postnatal day 3 ) on neurogenesis markers in dentate gyrus. This finding is interesting because mifepristone is currently being tested in a clinical trial for post-traumatic stress disorder (11), a condition, which has also been linked with maternal PTSD (12), and childhood trauma (13). Loi et al. also speculate about the implications of findings in animal models of perinatal stress for the study of human brain development and vulnerability to psychopathology. Cinini et al. explore the effects of adversity in an early postweaning period on hippocampal neurogenesis (14). The authors showed that social isolation in young (8-10 months old) nonhuman primates (marmosets) produced anxiety-like behaviors, elevated cortisol levels, and reduced neurogenesis.

Long-term effects of perinatal stress experiences are partially mediated by mother-pup interactions (15). How these interactions influence offspring development is summarized in the minireview by Lucion and Bortolini (16) where the special role of genes, epigenetics, imprinting, neurohormones, and learning is outlined. The review by Rincon-Cortés and Sullivan continues on the same theme (17). It is explained that the development of rat odor aversion develops after postnatal day 10, when maternal absence can increase GCs and subsequently activate a fear-related amygdaladependent neurocircuit. The effects of maternal contact are also explored in the mini-review by Stamatakis et al., who summarize findings from their new model of neonatal learning (18). In order to investigate the effects of the early maternal environment, rat pups either receive the expected reward of maternal contact or are denied this reward on postnatal days 10-13. The two training conditions have differential consequences on brain activity, HPA axis function, cognition, and stress-related behavior.
The final paper, a human study, by Bader et al. (19) explores transgenerational effects of parental trauma in offspring. The findings replicate and extend previous findings regarding urinary cortisol levels in Holocaust survivor offspring (20-22). Authors observed that the low cortisol levels in association with maternal PTSD are additionally associated with maternal age at Holocaust exposure (a parallel effect on cortisol in offspring that is not related to maternal PTSD).

To conclude, the articles of this Research Topic have highlighted the importance of investigating the biological effects of early stressful factors of maternal origin on stress circuitry in order to comprehend resilience and susceptibility to physical and mental disorders. The introduction of modern methodologies (e.g., epigenetic analyses) can give traditional neurobiological findings (e.g., neurogenesis markers) a molecular understanding.

\section{ACKNOWLEDGMENTS}

We wish to thank the authors for their excellent contributions, and the reviewers for their outstanding reports. We also wish to thank the Frontiers in Endocrinology editorial board, editorial assistants, and editors-in-chief for their work and advice, and for their trust in this project, particularly Dr. Hubert Vaudry, who was assigned to this Research Topic.

\section{REFERENCES}

1. Daskalakis NP, Bagot RC, Parker KJ, Vinkers CH, de Kloet ER. The three-hit concept of vulnerability and resilience: toward understanding adaptation to early-life adversity outcome. Psychoneuroendocrinology (2013) 38(9):1858-73. doi:10.1016/j.psyneuen.2013.06.008

2. Daskalakis NP, Yehuda R. Site-specific methylation changes in the glucocorticoid receptor exon $1 \mathrm{~F}$ promoter in relation to life adversity: systematic review of contributing factors. Front Neurosci (2014) 8:369. doi:10.3389/fnins.2014.00369

3. Yehuda R, Daskalakis NP, Lehrner A, Desarnaud F, Bader HN, Makotkine I, et al. Influences of maternal and paternal PTSD on epigenetic regulation of the glucocorticoid receptor gene in Holocaust survivor offspring. Am J Psychiatry (2014) 171(8):872-80. doi:10.1176/appi.ajp.2014.13121571

4. Hornung OP, Heim CM. Gene-environment interactions and intermediate phenotypes: early trauma and depression. Front Endocrinol (2014) 5:14. doi:10. 3389/fendo.2014.00014

5. Maniam J, Antoniadis C, Morris MJ. Early-life stress, HPA axis adaptation, and mechanisms contributing to later health outcomes. Front Endocrinol (2014) 5:73. doi: $10.3389 /$ fendo. 2014.00073

6. Raineki C, Hellemans KG, Bodnar T, Lavigne KM, Ellis L, Woodward TS, et al. Neurocircuitry underlying stress and emotional regulation in animals prenatally exposed to alcohol and subjected to chronic mild stress in adulthood. Front Endocrinol (2014) 5:5. doi:10.3389/fendo.2014.00005

7. Borges S, Coimbra B, Soares-Cunha C, Ventura-Silva AP, Pinto L, Carvalho MM, et al. Glucocorticoid programing of the mesopontine cholinergic system. Front Endocrinol (2013) 4:190. doi:10.3389/fendo.2013.00190

8. de Kloet ER, Claessens SEF, Kentrop J. Context modulates outcome of perinatal glucocorticoid action. Front Endocrinol (2014) 5:100. doi:10.3389/fendo.2014. 00100

9. Daskalakis NP, Enthoven L, Schoonheere E, de Kloet ER, Oitzl MS. Immediate effects of maternal deprivation on the (Re)activity of the HPA axis differ in CD1 and C57Bl/6J mouse pups. Front Endocrinol (2014) 5:190. doi: $10.3389 /$ fendo. 2014.00190

10. Loi M, Koricka S, Lucassen PJ, Joels M. Age- and sex-dependent effects of early life stress on hippocampal neurogenesis. Front Endocrinol (2014) 5:13. doi:10.3389/fendo.2014.00013

11. Golier JA, Caramanica K, Demaria R, Yehuda R. A pilot study of mifepristone in combat-related PTSD. Depress Res Treat (2012) 2012:393251. doi:10.1155/2012/ 393251 
12. Yehuda R, Bell A, Bierer LM, Schmeidler J. Maternal, not paternal, PTSD is related to increased risk for PTSD in offspring of Holocaust survivors. J Psychiatr Res (2008) 42(13):1104-11. doi:10.1016/j.jpsychires.2008.01.002

13. Breslau N, Chilcoat HD, Kessler RC, Davis GC. Previous exposure to trauma and PTSD effects of subsequent trauma: results from the Detroit area survey of trauma. Am J Psychiatry (1999) 156(6):902-7. doi:10.1176/ajp.156.6.902

14. Cinini SM, Barnabe GF, Galvao-Coelho N, de Medeiros MA, Perez-Mendes P, Sousa MB, et al. Social isolation disrupts hippocampal neurogenesis in young non-human primates. Front Neurosci (2014) 8:45. doi:10.3389/fnins.2014.00045

15. Claessens SE, Daskalakis NP, van der Veen R, Oitzl MS, de Kloet ER, Champagne DL. Development of individual differences in stress responsiveness: an overview of factors mediating the outcome of early life experiences. Psychopharmacology (Berl) (2011) 214(1):141-54. doi:10.1007/s00213-010-2118-y

16. Lucion AB, Bortolini MC. Mother-pup interactions: rodents and humans. Front Endocrinol (2014) 5:17. doi:10.3389/fendo.2014.00017

17. Rincon-Cortes M, Sullivan RM. Early life trauma and attachment: immediate and enduring effects on neurobehavioral and stress axis development. Front Endocrinol (2014) 5:33. doi:10.3389/fendo.2014.00033

18. Stamatakis A, Diamantopoulou A, Panagiotaropoulos T, Raftogianni A, Stylianopoulou F. Effects of an early experience involving training in a T-maze under either denial or receipt of expected reward through maternal contact. Front Endocrinol (2013) 4:178. doi:10.3389/fendo.2013.00178

19. Bader HN, Bierer LM, Lehrner A, Makotkine I, Daskalakis NP, Yehuda R. Maternal age at Holocaust exposure and maternal PTSD independently influence urinary cortisol levels in adult offspring. Front Endocrinol (2014) 5:103. doi:10.3389/fendo.2014.00103

20. Bierer LM, Bader HN, Daskalakis NP, Lehrner AL, Makotkine I, Seckl JR, et al. Elevation of 11beta-hydroxysteroid dehydrogenase type 2 activity in Holocaust survivor offspring: evidence for an intergenerational effect of maternal trauma exposure. Psychoneuroendocrinology (2014) 48:1-10. doi:10.1016/j.psyneuen. 2014.06.001

21. Lehrner A, Bierer LM, Passarelli V, Pratchett LC, Flory JD, Bader HN, et al. Maternal PTSD associates with greater glucocorticoid sensitivity in offspring of Holocaust survivors. Psychoneuroendocrinology (2014) 40(0):213-20. doi:10. 1016/j.psyneuen.2013.11.019

22. Yehuda R, Bierer LM. Transgenerational transmission of cortisol and PTSD risk. Prog Brain Res (2008) 167:121-35. doi:10.1016/S0079-6123(07)67009-5

Conflict of Interest Statement: The authors declare that the research was conducted in the absence of any commercial or financial relationships that could be construed as a potential conflict of interest.

Received: 02 December 2014; accepted: 22 December 2014; published online: 14 January 2015.

Citation: Daskalakis NP and Yehuda R (2015) Early maternal influences on stress circuitry: implications for resilience and susceptibility to physical and mental disorders. Front. Endocrinol. 5:244. doi: 10.3389/fendo.2014.00244

This article was submitted to Neuroendocrine Science, a section of the journal Frontiers in Endocrinology.

Copyright (C) 2015 Daskalakis and Yehuda. This is an open-access article distributed under the terms of the Creative Commons Attribution License (CC BY). The use, distribution or reproduction in other forums is permitted, provided the original author(s) or licensor are credited and that the original publication in this journal is cited, in accordance with accepted academic practice. No use, distribution or reproduction is permitted which does not comply with these terms. 